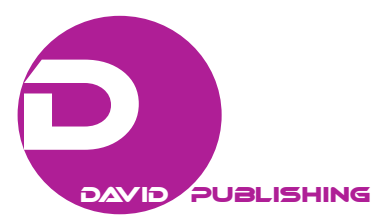

\title{
The Effect of Coaching and Team Effectiveness on Job Involvement for Logistics Industry Company
}

\author{
Chuang Yuh Shy \\ Chien Hsin University, Taiwan \\ Yi-Chung Hu, Lee Ping Chuan \\ Chung Yuan Christian University, Taiwan
}

\begin{abstract}
Logistics industry recently has worker's age problem, since the logistics industry has a hard working environment, also young age workers are lack of interest in labour intensive industries. Logistics industry requires a lot of stillness workers. Based on the basic labour and logistics management, it is a critical issue of possibilities to improve employees' job burnout, reduce work stress, and increase job involvement. Team effectiveness affecting self-efficacy, job involvement and social support which affect work performance is the major factor as in this research. This study empirically tests team effectiveness affects social support, self-efficacy, and job involvement. This study distributes questionnaires of a total of 270 samples, and 234 returned, the return ration is $86.6 \%$. The analysis technology used structural equation modeling (SEM) analysis as well.
\end{abstract}

Keywords: coaching, self-efficacy team effectiveness, social support, job involvement

\section{Introduction}

Besides organizing teams at the company structure are to cope with the fast-changing environment and increasing capability by use of the Internet. Distribution enterprises have realized only having good quality teams could improve the ability to solve problems, increase productivity, and make utilization of resources more efficiently. Quick (1992) believes teamwork has the advantages of cooperation between individuals and reduction of competition, making circulation of information faster and more extensive, communication channels smoother, utilization of resources more efficient, decision making more consensual and the time it takes to solve problems shorter, and related personnel more committed to execution of decisions.

Cohen and Ledford's (1994) studies point out that improvement of participation of team members can bring many benefits to the organization, including quality upgrades, production increases, and higher employee involvement. Today, management teams in enterprises stress the importance of giving employees certain authority, encouraging participation, innovation, and provision of information, and also emphasizing that members need to take responsibility (Deci \& Ryan, 1985). When employees become self-motivated to take part

Chuang Yuh Shy, Ph.D., International Business Department, Chien Hsin University, Taiwan.

Yi-Chung Hu, Ph.D., Business Administration Department, Chung Yuan Christian University, Taiwan.

Lee Ping Chuan, Ph. D. candidate, Business Administration Departmen, Chung Yuan Christian University, Taiwan.

Correspondence concerning this article should be addressed to Chuang Yuh Shy, International Business Department, Chien Hsin University, No. 229, Jiansing Rd., Jhongli Dist., Taoyuan City 32097, Taiwan. 
in tasks, the progress of operations can be left to the charge of the team members (Hackman, 1986). Once the management becomes less demanding, the organization will have more flexibility and managers will have more energy to complete other tasks, find out other issues that need to be addressed, engage in other long-term planning work, and handle external relations (Manz \& Sims, 1980).

However, Barry, Britten, Barber, Bradley, and Stevenson (1999) point out that the structure with only teamwork as the foundation cannot assure direct control of the conduct of employees on assembly lines. In practice, more teams have failed. Therefore, besides team systems, other measures also have to be taken to assure teamwork can be carried out in better ways and one of such measures is to allow employees to exercise their self-efficacy (Bandura, 1986), which means the ability of an individual to make assessment and execute a series of actions. In other words, the stress is not set on the technical capacity an individual has but on the ability of an individual to apply his or her skills to accomplish work.

Meanwhile, in response to the gaps in the distribution processing industry, Saleh and Hosek (1976) suggest job involvement can be influenced by the work environment and individual input. The situational factors at work can be easily affected by the environment in the organization and influence employees' job involvement. Such factors in the distribution processing industry include bad weather and messy surroundings. For this reason, hardworking and perseverant people are needed. However, facing aging population and young people's lack of interest in labor-intensive work, the logistics industry is badly in need of low-level employees. Meanwhile, in the distribution processing industry where labor is the foundation, occupational burnout is more likely to occur. As a result, enthusiasm and involvement drop. Under such circumstances, support from others and whether the coaching of team leaders is good enough to encourage involvement and boost work performance become important.

Distribution processing businesses are aware that if teaching, guidance, and encouragement can be provided through a coaching system to help staff members continue to improve work performance, upgrade skills, and develop careers (Krazmien \& Berger, 1997), work situations can become better. Enterprises have realized the talents they need are not individual fighters but leaders who can organize teams and lead them to grow and move toward excellence. When job involvement is low, social support is all the more significant. Colvin, Cullen, and Ven (2002) indicate that social support is multifarious. It includes individuals' feeling that they have support and friends and relatives or other people that mean something to them identifying with their sense of value and providing symbolic or substantive assistance. In other words, the key issue is whether the individuals in a team can get help through their personal relations or social backup and whether social support has an effect on their job involvement. For this reason, this study will be focused on the influence of coaching and team effectiveness on self-efficacy, social support, and job involvement.

\section{Literature Review}

\section{Coaching}

Managerial personnel have to be able to provide coaching ability (Evered \& Selman, 1989). Through a coaching system, they teach, guide, encourage, and give feedback to employees, as well as help their staff members improve work performance, upgrade skills, and develop careers (Krazmien \& Berger, 1997). In the aforesaid theories, learning and development are stressed. In general, as defined by most scholars, skill coaching is a strategy for organizational development. It can help employees promote their self-efficacy, performance, and job involvement. Through good interactions, managers can stimulate employees to bring out 
their maximum potential. Conventional management aims at solving technical problems by giving employees professional support, whereas coaching is an approach of management to train executives. While coaching, managers can stimulate creativity, see employees release their potential, and identify talented ones who can be promoted to be team leaders in the future. Based on the abovementioned, this study concludes that coaching can be adopted in management for supervisors to, with the interests of employees taken into consideration, confer proper authority to stimulate staff members to develop their potential, encourage employees, and help them solve their problems to increase productivity. However, it hasn't been indicated in too many studies whether coaching will have any negative effect on the development of self-efficacy in the distribution processing industry. This is a question that requires further exploration.

\section{Team Effectiveness}

As defined in the study by Guzzo and Salas (1995), a team is an organization of two or more people to independently accomplish their mutual targets. That is to say, a team has to include at least two people and they must have mutual targets. Meanwhile, Shonk (1982) defines that a team includes two or more people put together to complete a mutual mission through coordination. According to Maddux's (1993) study, the composition of a team involves many other important factors. Team members have to develop a sense of belonging to their work and to their unit, unconditionally contribute their professional skills and knowledge to the organization in order to achieve team targets, work under mutual trust for one another as well as openly express their ideas and opinions and communicate with sincerity, and understand that occurrence of conflicting ideas is a normal phenomenon during interactions and take constructive measures to solve conflicts. Therefore, the biggest difference between a team and an individual is that consensus is required in a team. Without consensus, team performance will be accredited to individuals and team effectiveness will decline. On the contrary, when consensus is achieved, the team will become an effective unit to consolidate group performance (Katzenback \& Smith, 1993). Team members need to trust and rely on one another in their pursuit of mutual targets. They must also cooperate and take active part in teamwork.

Based on the above mentioned definitions from different scholars, a team is defined in this study as a working group composed of people who can complement, rely on, and cooperate with one another to accomplish their mutual target through coordination and communication. They also have to take responsibility whether the work is successful or not. As for team effectiveness, many studies have indicated that the approaches of work can help improve job involvement. Nonetheless, there is no consistent conclusion with regard to whether such approaches can increase productivity or performance of lower-level employees (Banker, Field, Schroeder, \& Sinha, 1996; Cohen \& Ledford, 1994). Apparently, different indices adopted in measurement of team effectiveness can lead to dissimilar study results. Since this study is conducted on the distribution processing industry, the productivity of lower-level employees is the main concern; hence, the connotation of team effectiveness requires further discussion.

\section{Social Support}

Social support refers to emotional, moral, and material support that an individual is able to get, officially or unofficially, from another member, the group or environment to help the individual overcome frustrations or pressure (Caplan, 1974). Meanwhile, Norbeck, Lindsey, and Carrieri (1981) suggest that social support is multifarious. It is when an individual feels through personal relations the love and care that relatives, friends and others give to him or her as well as the affirmation and recognition of his or her sense of value. At the same 
time, these people might also offer symbolic or substantive assistance. In other words, it means such an individual can get help through personal networks and social support (Colvin et al., 2002). According to Caplan's (1974) definition, social support is like a message that makes an individual have the sense of belonging to a group and feel loved and cared for. In the meantime, from the perspective of providers, social support is given to increase resources for the recipient. Such resources include actual assistance, feedback, information, counseling, and encouragement. Social support can not only reduce stress but also lead to tangible results (Shumaker \& Brownell, 1984).

\section{Job Involvement}

Kanungo (1982) points out that work commitment can be divided into work focus and job involvement. The former refers to the level of importance of work in the personal life of an individual. Being the outcome of socialization, it does not change easily with the external environment. The latter means the promise of an individual to concentrate on work and pay attention to the work condition all the time. In the meantime, Robbins (2001) points out that job involvement includes two aspects. The first is the level of enthusiasm about the work and the second is stronger identification with the work than others. From the aforesaid studies, it can be reckoned that scholars define job involvement differently. Kanungo (1982) also points out that job involvement is a result of socialization and a part of a person's sense of value. An individual may be highly involved in his or her work but may not necessarily consider work as a very important part of his or her life. Lodahl and Kejner (1965) define that the term "job involvement" as "an individual's identification with his or her work or the significance of work in his or her self image", also point out that "job involvement means work performance and has an effect on self-esteem." However, as the hypothetic premise of this definition being "job involvement is the sense of value that takes form at an early stage of socialization," if an individual's sense of value towards work does not change, his or her job involvement will not become different in consequence of job changes.

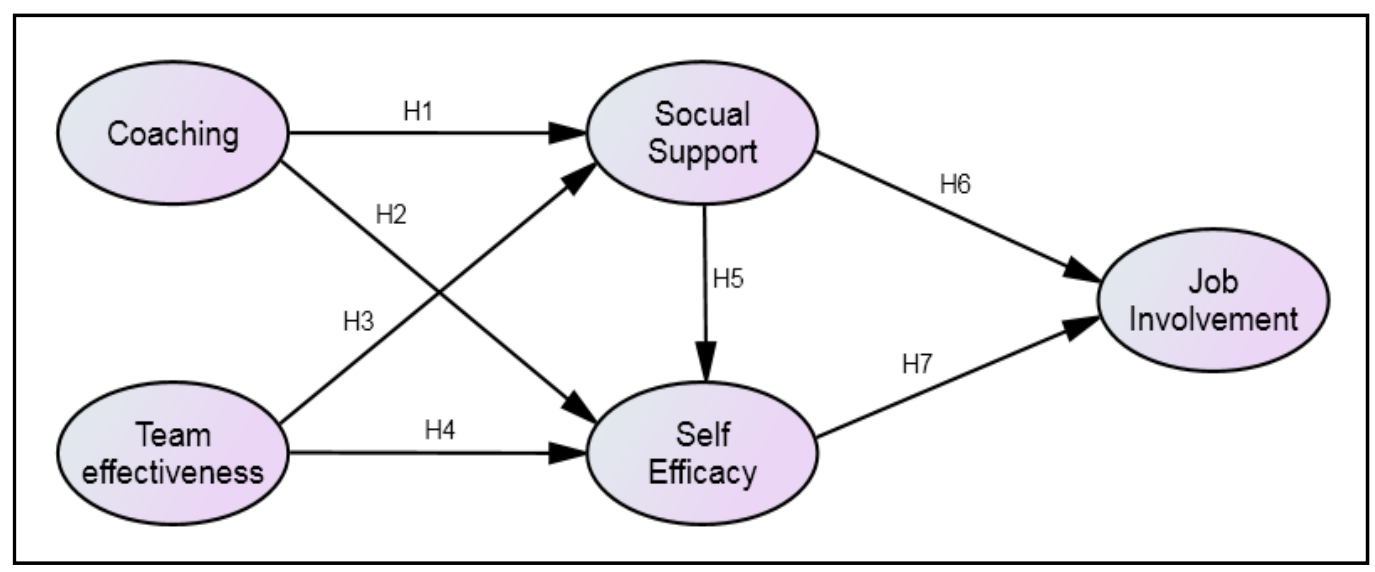

Figure 1. Study framework.

\section{Self-efficacy}

Bandura (1977) was the first to propose the idea of self-efficacy in a systematic approach. According to Bandura's (1986) study, self-efficacy is the ability of an individual to assess a series of actions that he or she is to execute. It is not the technical capacity of an individual that is emphasized, but his or her ability to evaluate his or her capacity to apply skills to accomplish a mission. As pointed out by Bandura (1971), based on social 
learning theories, the strength of people's self-belief determines whether they will try hard to cope with difficult situations. According to Luszczynska, Scholz, and Schwarzer's (2005) study, self-efficacy is usually situation-specific, but individuals can also have a generalized sense of self-efficacy that reflects itself overall estimate of personal competence in dealing with a variety of stressful situations.

In the empirical self-efficacy study that is similar to the general workplace, coaching training self-efficacy beliefs have been shown to positively relate to training performance (Bell \& Kozlowski, 2008; Colquitt, LePine, \& Noe, 2000; Hughes, Day, Wang, Schuelke, Arsenault, Harkrider, \& Cooper, 2013).

\section{Hypotheses}

Coaching is to increase resources for the recipient. Such resources include actual assistance, feedback, information, counseling, and encouragement. The support can not only reduce stress but also lead to tangible results (Shumaker \& Brownell, 1984). The learning experiences from coaching may affect work outcome and reduce stress in the work environment. Moen and Allgood (2009) suggested that increased job insight and professional skills from coaching will meet the job demand. The learning outcomes from coaching may affect the subjective appraisal of job demand. Moen and Skaalvik (2009) found that executive coaching enhanced performance psychology variables, such as self-efficacy and self-determination. Social support from supervisors and colleagues is reported to reduce stress (Peterson, Bergstrom, Samuelson, Asberg, \& Nygren, 2008). Coaching not only enhances the strong social support battle the stress from job demand also increases social support from supervisors and colleagues. Bush (2004) found that effects of coaching on social support are more actively engaged by their colleagues in giving feedback, discussing ideas for improvements with other team workers. Based on this, the hypothesis that the recipient is willing to accept when the provider conducts coaching to the recipient is proposed.

H1: Coaching will have positively significant influence on social support.

Coaching is conducted to help staff members continue to improve work performance, upgrade skills, and develop careers (Krazmien \& Berger, 1997). The emphasis is placed on the coach being a good teacher and a friend at the same time and able to give support and encouragement especially when people encounter problems to persuade them they have the ability to break through and make them try harder. Such persuasion can lead to success and help the encouraged develop self-efficacy (Bandura, 1997). Based on this, the hypothesis that timely encouragement from the supervisor or a superior will have an effect on self-efficacy is proposed.

$\mathrm{H} 2$ : Coaching will have positively significant influence on self-efficacy.

The stronger the social support an individual receives in a team, the less likely this individual will feel alienated when given assignments. In other words, this individual will have a stronger feeling of interdependence about the team and increase the level of interdependence to enhance team performance. Results of related studies show that the stronger the social support from the team an individual feels, the stronger the confidence of the individual will have in his or her ability to improve work efficiency. Deeter-Schmelz and Ramsey (1997) also suggest that in a teamwork environment, social support can have strong influence on work results. As pointed out by Campion (1993), when team members help one another and have active socializing interactions, the efficiency of the team will improve. Based on this, the hypothesis that the more encouraging the other members in a team are, the stronger the identification with the team will be is proposed. 
H3: Team effectiveness will have positively significant influence on social support.

Parker (1990) indicates that a team leader has key influence on team effectiveness. An effective team leader is also a good manager and a team member. A leader must be able to set clear and precise targets and prospects for the team and push individual members to make efforts accordingly while feeling happy to be working with the others. At the same time, when there are members with experience, they can have effective influence on development of self-efficacy. As pointed out by Bandura (1997), individuals develop their self-efficacy in accordance with their successes or failures in the past and also perform initial interpretations of results of their actions accordingly. Successful experiences can increase their expectations for their abilities whereas repeated failures will lead to self-doubt and decline of self-efficacy. Therefore, perfection of team effectiveness will have an effect on development of self-efficacy. Based on this, the following hypothesis is proposed.

H4: Team effectiveness will have positively significant influence on self-efficacy.

According to Caplan (1974), social support refers to emotional, moral, and material support that an individual is able to get, officially or unofficially, from another member, the group or environment to help the individual overcome frustrations or pressure. Meanwhile, as indicated by Bandura (1977), in social persuasion aiming to help develop self-efficacy, the emphasis is placed on the coach being a good teacher and a friend at the same time and able to give support and encouragement especially when people encounter problems to persuade them they have the ability to break through and make them try harder. Such persuasion can lead to success and help the encouraged develop self-efficacy. Based on this, the hypothesis that providing appropriate encouragement to support others can enhance their ability to cope with difficult situations is proposed.

H5: Social support has positively significant influence on self-efficacy.

Kanungo (1982) suggests the level of an employee's job involvement can be affected by the mentality and behavior of the other members of the organization. In the meantime, according to the buffer theory put forth by H. F. Antonovsky and A. Antonovsky (1974), social support provides buffers to protect people from pressure in daily life. The buffering effects are mainly to provide cognitive guidance and information and resources needed to cope with pressure. Individuals with more social support will be subject to fewer factors that have influence on their physical being and mentality. Therefore, social support is considered to have buffering effects. Cohen and Wills (1985) think positive social relationships can help individuals deal with negative psychological conditions (such as anxiety, depression, etc.). Through networks of social relations, individuals can get emotional support and affirmation of their self-worth to enhance their capacity to face changes in life. Based on this, the hypothesis that the buffering effects of social support can have an effect on job involvement is proposed.

H6: Social support has positively significant influence on job involvement.

Vicarious experience in self-efficacy means that when seeing the success of people with abilities similar to their own and the praise received, individuals can convince themselves that they can also do the same and succeed (Bandura, 1986) and, as a result, develop the feeling that they need. Kanungo (1982) believes job involvement is the consequence of whether the needs of employees are satisfied. The stronger the feeling that their needs are satisfied, the more intense the job involvement of the employees will be. Based on this, the hypothesis that vicarious experience can increase one's confidence at work and job involvement is proposed.

H7: Self-efficacy has positively significant influence on job involvement. 


\section{Methods}

\section{Data Analysis}

IBM SPSS Statistics 20 and AMOS 20.0 are adopted for statistical power and data analysis. The statistical methods applied in this study include reliability and validity analysis, and mean and standard deviation analysis. Structural equation modeling is used to analyze the hypothetical relations between the variables in the study mode to test whether the study mode and the hypotheses are valid and also analyze the overall model.

\section{Sample Data}

This study is intended to understand the influence of coaching and team performance on job involvement through provision of social support and development of self-efficacy. A questionnaire survey was conducted on people working in the distribution processing industry through convenient sampling. Two hundred and eighty copies of questionnaire were issued and 250 were retrieved. After subtraction of 16 samples with misplaced answers, unanswered questions, and intentionally given wrong answers, 234 copies were valid. The response rate was $83.5 \%$.

\section{Definition of Variables}

Coaching is defined as the guidance and feedback given to distribution and processing workers by their supervisors. The study tool is designed in reference to the one adopted in Hagen and Peterson (2014) for measurement. The scale includes 16 questions covering four dimensions, namely open communication, team-orientation, respect for individuals, and pursuit of development.

Team effectiveness is defined as the effect of communication between distribution processing workers on team operation. The study tool is a revised version of the scale applied in the Influence of Team Leaders on Collective Effectiveness and Team Performance (Tjosvold, 1988). It includes 29 questions covering the four aspects of team performance, team attitude, team commitment, and team cooperation.

Social support is defined as the reactions of logistics workers to emotional and moral support. The study tool (MSPSS; G. D. Zimet, Dahlem, S. G. Zimet, \& Farley, 1988) includes 12 questions covering the three dimensions of family, friends, and specific people.

Self-efficacy is defined as the cognitive perception of distribution processing workers toward cause-and-effect relations in different situations. The study tool (Caikang, 2000) includes 10 questions covering the dimensions of anxiety to test the sell-efficacy and ways of coping.

Job involvement is defined as the unswerving commitment of logistics workers and their concerns about their work as a result of personal experiences and the current environment. The study tool (Measurement of Job and Job Involvement by Kanungo, 1982) includes 10 questions.

\section{Results}

\section{Reliability and Validity Analysis}

The questionnaire covers five dimensions: coaching, self-efficacy, team effectiveness, social support, and job involvement. The number of questions regarding the different dimensions is 20 about five aspects of coaching, 10 about self-efficacy, 29 about four aspects of team effectiveness, 12 about three aspects of social support, and 10 about job involvement. After the questionnaire was designed, it was presented to be inspected by five specialists for wording modification. Subsequently, 50 copies were issued for a pretest. Afterwards, reliability and validity analysis was performed and items with inadequate reliability and factor loads larger than 
0.5 were deleted. Finally, the questionnaire containing 81 questions about all the aspects was administered, retrieved, and statistically processed. The Cronbach's $\alpha$ and confirmatory factor analysis were applied to evaluate reliability and validity. According to Nunnally (1978), reliability coefficients larger than 0.7 are considered decent for basic research. The Cronbach's $\alpha$ values of the scales for different dimensions all exceeded $0.7,0.963$ for the total aspects of social support, 0.897 for job involvement, 0.963 for self-efficacy, 0.977 for coaching, and 0.985 for team effectiveness. Apparently, the reliability of the questions regarding each dimension is rather high.

\section{Validity Analysis}

Convergent validity analysis. In the confirmatory factor analysis, composite reliability (CR) is adopted as the standard in measurement of the reliability of potential aspects. The composite reliability value of the potential aspects concerns the consistency of the aspects measured. The higher the reliability, the higher the internal consistence will be. Initially, the reliability of the variables inspected has to be larger than 0.50 (Jöreskog \& Sörbom, 1989). Then, the composite reliability must be examined. As suggested by Fornell and Larcker (1981), the CR value had better be over 0.6. After the questions regarding each dimension were tested, each standard load turned out to be larger than 0.7. First, it was necessary to check whether the reliability of each variable was larger than 0.50 (Hair, Black, Babin, Anderson, \& Tatham, 2009). The tests performed revealed the $\mathrm{CR}$ value for each dimension was larger than 0.7 , indicating the four scales had rather decent reliability.

The AVE values of the aspects in the coaching scale were respectively $0.784,0.885,0.845$, and 0.697 . The AVE values of the aspects in the team effectiveness scale were $0.785,0.828,0.712$, and 0.897 . The AVE values of the aspects in the social support scale were $0.823,0.780$, and 0.867 . The AVE value of the aspect in the self-efficacy scale was 0.572 . The AVE value of the aspect in the job involvement scale was 0.572 . All the aspects complied with the suggestion from Hair et al. (2009) that the AVE values should be larger than 0.5.

Common method variance. Common method variance (CMV) refers to a kind of systemic bias as a result of the ways of measurement adopted in research. Causes are many, such as features and contexts of questions. To prevent occurrence of CMV when people fill in answers, slack single-factor CFA CMV tests were applied, including single factor confirmatory analysis, with the $\chi^{2}$ being $3,763.601(\mathrm{df}=464), \chi^{2} / \mathrm{df}$ (Chi square value/degree of freedom) being 8.111, and other goodness-of-fit indicators: GFI $=0.408$, AGFI $=0.0326, \mathrm{CFI}=$ $0658, \mathrm{TLI}=0.634, \mathrm{SRMR}=0.902$, and RMSEA $=0.175$.

In the multi-factor confirmatory factor analysis, the $\chi^{2}$ value was $2,136.717(\mathrm{df}=454)$, the $\chi^{2} / \mathrm{df}(\mathrm{Chi}$ square value/degree of freedom) 4.706 , and other goodness-of-fit indicators: $\mathrm{GFI}=0.597, \mathrm{AGFI}=0.532, \mathrm{CFI}=$ $0.826, \mathrm{TLI}=0.809$, SRMR $=0.902$, and $\mathrm{RMSEA}=0.126$.

The two models $\Delta \mathrm{df}=65-59=6, \Delta \chi^{2}=3,736.601-2,136.717=1,599.884$. The $\Delta$ value was larger than 1.96. The difference achieved significance $p<0.000$, meaning the null hypothesis was rejected. Therefore, the models were different and no bias would occur in coefficient estimation. In other words, there would be no confusion in presentation of conclusions.

Overall mode goodness of fit. In this study, dimensional measurement is conducted in stages on team effectiveness, coaching, social support, self-efficacy, and job involvement in the distribution processing industry. The results from the measurement are shown in Table 1. 
Table1

Overall Model Fit

\begin{tabular}{llllll}
\hline & $\begin{array}{l}\text { Evaluation } \\
\text { standard }\end{array}$ & Range & $\begin{array}{l}\text { Evaluation } \\
\text { standard }\end{array}$ & $\begin{array}{l}\text { Initial model } \\
\text { test result }\end{array}$ & Study result \\
\hline & $\chi^{2} / \mathrm{df}$ & The smaller the & $<5$ & 4.769 & 4.562 \\
& GFI & $0-1$ & $>0.9$ & 0.595 & 0.607 \\
& AGFI & $0-1$ & $>0.9$ & 0.531 & 0.542 \\
Absolute goodness of fit index & RMR & - & $<$ The smaller & 0.251 & 0.253 \\
& SRMR & $0-1$ & the better & 0.970 & 0.0969 \\
& RMSEA & $0-1$ & $<0.05$ & 0.127 & 0.124 \\
\hline \multirow{5}{*}{ Parsimonious goodness of fit index } & PGFI & $0-1$ & $<0.08$ & 0.514 & 0.521 \\
& PCFI & $0-1$ & $>0.5$ & 0.756 & 0.764 \\
& PNFI & $0-1$ & $>0.5$ & 0.722 & 0.731 \\
\hline \multirow{5}{*}{ Incremental goodness of fit index } & NFI & $0-1$ & $>0.9$ & 0.786 & 0.798 \\
& NNFI/TLI & $0-1$ & $>0.9$ & 0.806 & 0.819 \\
& CFI & $0-1$ & $>0.9$ & 0.822 & 0.834 \\
\hline
\end{tabular}

\section{Hypothesis Testing}

Table2

AMOS Output for Model Hypotheses Test

\begin{tabular}{llllll}
\hline Hypothesis & $\begin{array}{l}\text { Unstandardized } \\
\text { estimate }\end{array}$ & $\begin{array}{l}\text { Standard } \\
\text { deviation }\end{array}$ & CR value & $P$-value & Sig. \\
\hline H1 coaching and social support & 0.24 & 0.152 & 1.584 & 0.36 & No \\
H2 coaching and self-efficacy & -0.201 & 0.119 & 1.696 & 0.36 & No \\
H3 team effectiveness and social support & 0.622 & 0.083 & 7.513 & 0.01 & Yes \\
H4 team effectiveness and self-efficacy & 0.559 & 0.077 & 7.304 & 0.00 & Yes \\
H5 social support and self-efficacy & 0.356 & 0.067 & 5.295 & 0.00 & Yes \\
H6 social support and job involvement & 0.351 & 0.09 & 3.86 & 0.01 & Yes \\
H7 self-efficacy and job involvement & 0.301 & 0.090 & 3.335 & 0.01 & Yes \\
\hline
\end{tabular}

In the relation between coaching and social support, the unstandardized estimate is 0.240 , standard deviation $=0.152, \mathrm{CR}$ value $1.584, p$-value $=0.36$, and standardized path coefficient $=0.141$, indicating significance. The study data show reversely significant influence; therefore, H1 is not significant.

In the relation between coaching and self-efficacy, the unstandardized estimate is -0.201 , standard deviation $=0.119, \mathrm{CR}$ value $1.696, p$-value $=0.36$, and standardized path coefficient $=-0.124$, indicating significance. The study data show reversely significant influence; therefore, H2 is not significant.

In the relation between team effectiveness and social support, the unstandardized estimate is 0.622 , standard deviation $=0.083, \mathrm{CR}$ value $7.513, p$-value $=0.01$, and standardized path coefficient $=0.710$, indicating significance. The study data show positively significant influence; therefore, $\mathrm{H} 3$ is valid.

In the relation between team effectiveness and self-efficacy, the unstandardized estimate is 0.559 , and standard deviation $=0.077, \mathrm{CR}$ value $7.304, p$-value $=0.00$, standardized path coefficient $=0.669$, indicating significance. The study data show positively significant influence; therefore, $\mathrm{H} 4$ is valid.

In the relation between social support and self-efficacy, the unstandardized estimate is 0.356 , standard deviation $=0.067, \mathrm{CR}$ value $5.295, p$-value $=0.00$, and standardized path coefficient $=0.373$, indicating significance. The study data show positively significant influence; therefore, H5 is valid. 
In the relation between social support and job involvement, the unstandardized estimate is 0.351 , standard deviation $=0.090, \mathrm{CR}$ value $3.860, p$-value $=0.01$, standardized path coefficient $=0.433$, indicating significance. The study data show positively significant influence; therefore, H6 is valid.

In the relation between self-efficacy and job involvement, the unstandardized estimate is 0.301 , standard deviation $=0.090, \mathrm{CR}$ value $3.335, p$-value $=0.01$, standardized path coefficient $=0.3534$, indicating significance. The study data show positively significant influence; therefore, $\mathrm{H} 7$ is valid.

\section{Conclusions}

The results of this study indicate that team effectiveness, social support, and self-efficacy have positively significant influence on job involvement, but the influence of coaching on self-efficacy and social support appears to be reverse and insignificant. In a work environment of the conventional logistics industry, the needs of professional knowledge teaching and skill coaching are not so strong. Employees cannot feel the effect of coaching and, as a result, the effect of coaching on self-efficacy is not obvious. Employees are unable to improve their self-efficacy after receiving skill coaching from their supervisors. McClelland and Boyatzis (1982) think giving authority and responsibility to employees can increase their ability. This means the motivation to perform better at work can be achieved through improvement of self-efficacy. In this study, coaching has no significant influence on social support probably because coaching of professional knowledge in the logistics industry is carried out through established modes and requires no communication. Employees have no deep perceptions of corporate concepts meant to be conveyed through coaching. They have no intention to make career planning and cannot do anything about the ways promotions are given; hence, they are unable to feel the benefits of support from families, friends, peers, and coaching. When pressure from work occurs, the intensity of self-belief determines whether they will make efforts to cope with difficult situations. Heller and Swindle (1983) point out that individuals with more social support will be less likely to be subject to factors that have effects on their mentality and physical being; therefore, social support is considered to have buffering effects. Logistics workers set accomplishment of team targets as the top priority. Team members have their own expertise and are able to support and cooperate with one another. Under such circumstances, they will be able to clearly and openly communicate to complete work and job involvement and enthusiasm to participate will be upgraded.

\section{Study Limitations}

Convenience sampling was adopted to conduct a questionnaire survey on logistics workers in northern Taiwan only. Plus, the samples were retrieved a month later. Therefore, the influence of the frame of mind of the people at the time of filling out the questionnaire and other factors that might have affected the authenticity of the answers on the results of the study cannot be ruled out. Moreover, the questionnaire was filled out by just a portion of logistics workers. Whether the results can speak for the management condition of the entire industry remains an issue to be looked into.

\section{References}

Antonovsky, H. F., \& Antonovsky, A. (1974). Commitment in an Israeli kibbutz. Human Relations, 27(3), 303-319.

Bandura, A. (1971). Social learning theory. Chicago, IL: Aldine Atherton.

Bandura, A. (1977). Self-efficacy: Toward a unifying theory of behavior change. Psychological Review, 84(2), 191-215.

Bandura, A. (1986). Social foundations of thought and action: A social cognitive theory. Englewood Cliffs, NJ: Prentice-Hall. 
Bandura, A. (1997). Self-efficacy: The exercise of control. New York: W. H. Freeman.

Banker, R. D., Field, J. M., Schroeder, R. G., \& Sintia, K. K. (1996). Impact of work teams on manufacturing performance: A longitudinal field study. Academy of Management Journal, 39(4), 867-890.

Barry, C. A., Britten, N., Barber, N., Bradley, C., \& Stevenson, F. (1999). Using reflexivity to optimize teamwork in qualitative research. Qualitative Health Research, 9(1), 26-44.

Bell, B. S., \& Kozlowski, S. W. J. (2008). Active learning: Effects of core training design elements on self-regulatory processes, learning, and adaptability. Journal of Applied Psychology, 93(2), 296-316.

Bush, M. W. (2004). Client perceptions of effectiveness in executive coaching (Unpublished doctoral thesis). Pepperdine University.

Caikang, W. (2000). An exploration of analysis of variance by items: What is it? Journal of Chinese Psychology Acta Psychologica Sinica, 2, 017.

Campion, M. A. (1993). Article review checklist: A criterion checklist for reviewing research articles in applied psychology. Personnel Psychology, 46(3), 705-718.

Caplan, G. (1974). Support systems and community mental health: Lectures on concept development. Behavioral Publications.

Cohen, S. G., \& Ledford, J. G. E. (1994). The effectiveness of self-managing teams: A quasi-experiment. Human Relations, 47(1), 13-43.

Cohen, S., \& Wills, T. A. (1985). Stress, social support, and the buffering hypothesis. Psychological Bulletin, 98(2), 310.

Colquitt, J. A., LePine, J. A., \& Noe, R. A. (2000). Toward an integrative theory of training motivation: A meta-analytic path analysis of 20 years of research. Journal of Applied Psychology, 85(5), 678-707.

Colvin, M., Cullen, F. T., \& Ven, T. V. (2002). Coercion, social support, and crime: An emerging theoretical consensus. Criminology, 40(1), 19-42.

Deci, E. L., \& Ryan R. M. (1985). Intrinsic motivation and self-determination in human behavior. Harvard Business Review, 82(10), 122-130.

Deeter-Schmelz, D. R., \& Ramsey, R. P. (1997). Considering sources and types of social support: A psychometric evaluation of the House and Wells (1978) instrument. The Journal of Personal Selling and Sales Management, 49-61.

Ellinger, A. E., \& Keller, S. B. (2003). Supervisory coaching behavior, employee satisfaction, and warehouse employee performance: a dyadic perspective in the distribution industry. Human Resource Development Quarterly, 14(4), $435-458$.

Evered, R. D., \& Selman, J. C. (1989). Coaching and the art of management. Organizational Dynamics, 18(2), 16-32.

Fornell, C., \& Larcker, D. F. (1981). Structural equation models with unobservable variables and measurement error: Algebra and statistics. Journal of Marketing Research, 382-388.

Guzzo, R. A., \& Salas, E. (1995). Team effectiveness and decision making in organizations (Vol. 22). Pfeiffer.

Hackman, J. R. (1986). The psychology of self-management in organizations. In M. S. Pallak and R. O. Perloff (Eds.), The Master lectures, Vol. 5, Psychology and work: Productivity, change, and employment (pp. 89-136).

Hagen, M. S., \& Peterson, S. L. (2014). Coaching scales: A review of the literature and comparative analysis. Advances in Developing Human Resources, 16(2), 222-241.

Hair, J. F., Black, W. C., Babin, B. J., Anderson, R. E., \& Tatham, R. L. (2009). Análise multivariada de dados. Bookman Editora.

Heller, K., \& Swindle, R. W. (1983). Social networks, perceived social support, and coping with stress. Preventive Psychology: Theory, Research and Practice, 87-103.

Hughes, M. G., Day, E. A., Wang, X., Schuelke, M. J., Arsenault, M. L., Harkrider, L. N., \& Cooper, O. D. (2013). Learner-controlled practice difficulty in the training of a complex task: Cognitive and motivational mechanisms. Journal of Applied Psychology, 98(1), 80-98.

Jöreskog, K. G., \& Sörbom, D. (1989). LISREL 7: A guide to the program and applications. Spss.

Kanungo, R. N. (1982). Measurement of job and work involvement. Journal of applied psychology, 67(3), 341-350.

Katzenback, J. R., \& Smith, D. K. (1993). The wisdom of teams. New York, NY: Harper Bussiness.

Krazmien, M., \& Berger, F. (1997). The coaching paradox. International Journal of Hospitality Management, 16(1), 3-10.

Lodahl, T. M., \& Kejnar, M. (1965). The definition and measurement of job involvement. Journal of Applied Psychology, 49(1), 24.

Luszczynska, A., Scholz, U., \& Schwarzer, R. (2005). The general self-efficacy scale: Multicultural validation studies. Journal of Psychology, 139(5), 439-457.

Maddux, J. E. (1993). Social cognitive models of health and exercise behavior: An introduction and review of conceptual issues. Journal of Applied Sport Psychology, 5(2), 116-140. 
Manz, C. C., \& Sims, H. P. (1980). Self-management as a substitute for leadership: A social learning theory perspective. Academy of Management Review, 5(3), 361-367.

McClelland, D. C., \& Boyatzis, R. E. (1982). Leadership motive pattern and long-term success in management. Journal of Applied Psychology, 67(6), 737.

Moen, F., \& Allgood, E. (2009). Coaching and the effect on self-efficacy. Organization Development Journal, 27(4).

Moen, F., \& Skaalvik, E. (2009). The effect from executive coaching on performance psychology. International Journal of Evidence Based Coaching and Mentoring, 7(2), 31-49.

Multidimensional Scale of Perceived Social Support (MSPSS; Zimet, Dahlem, Zimet, \& Farley, 1988).

Norbeck, J. S., Lindsey, A. M., \& Carrieri, V. L. (1981). The development of an instrument to measure social support. Nursing Research, 30(5), 264-269.

Nunnally, J. (1978). Psychometric methods. New York: McGraw-Hill.

Parker, G. (1990). Whose care? Whose costs? Whose Benefit? A critical review of research on case management and informal care. Ageing and Society, 10(04), 459-467.

Peterson, U., Bergstrom, G., Samuelson, M., Asberg, M., \& Nygren, A. (2008). Reflecting peer support groups in the prevention of stress and burnout: Randomized controlled trial. Journal of Advanced Nursing, 63(5), 506-516.

Quick, T. L. (1992). Successful team building. New York: American Management Association.

Robbins, S. P. (2001). Organizational behavior (9th ed.). Upper Saddle River, NJ: Prentice-Hall Inc.

Saleh, S. D., \& Hosek, J. (1976). Job involvement: Concepts and measurements. Academy of Management Journal, 19(2), 213-224.

Shonk, J. H. (1982). Working in teams: A practical manual for improving work groups. Amacom.

Shumaker, S. A., \& Brownell, A. (1984). Toward a theory of social support: Closing conceptual gaps. Journal of Social Issues, 40(4), 11-36.

Tjosvold, D. (1988). Cooperative and competitive interdependence: Collaboration between departments to serve customers. Group \& Organization Studies, 13(3), 274-289.

Torkzadeh, G., Koufteros, X., \& Pflughoeft, K. (2003). Confirmatory analysis of computer self-efficacy. Structural Equation Modeling, 10(2), 263-275.

Zimet, G. D., Dahlem, N. W., Zimet, S. G., \& Farley, G. K. (1988). The multidimensional scale of perceived social support. Journal of Personality Assessment, 52(1), 30-41. 